\title{
Expanding teachers' technological pedagogical reasoning with a systems pedagogical approach
}

\author{
Margaret L. Niess \\ Oregon State University \\ Henry Gillow-Wiles \\ Southern Oregon University
}

\begin{abstract}
A systems approach provides insight for expanding teachers' pedagogical reasoning for integrating multiple technologies in inquiry, communication, and collaboration. An online learning trajectory supports the integration of a systems pedagogical approach for guiding teachers in developing their technological pedagogical thinking and reasoning so they in turn are able to implement a systems pedagogical approach with their own students. Specific instructional strategies guide teachers in refining their mental models for integrating multiple technologies in teaching mathematics through their increasingly complex technological pedagogical understanding as they learn about the technologies and teaching with those technologies. This study focuses on the impact that a system of multiple technologies as pedagogical tools has on teachers' technological pedagogical reasoning as they integrate multiple technologies in their classrooms. A systems pedagogical understanding is at the core of teachers' enhancement of their technological pedagogical reasoning, and supports the transformation of their knowledge called technological pedagogical content knowledge.
\end{abstract}

\section{Introduction}

The explosion of technologies in the twenty-first century has resulted in the availability of an exciting venue of new and emerging forms of inquiry, communication, and collaboration. With the enhanced capabilities of these technologies, evidence shows an exponential rise in the ability to access multiple and diverse instructional methods that result in deeper and more thoughtful learning. Today's students have become accustomed to gathering information quickly, using more advanced technologies to accomplish more than they were able to do in the previous century (International Society for Technology in Education [ISTE], 2016; Partnership for 21st Century Learning, 2015; Prensky, 2001; Thoughtful Learning Organization, 2016). They use graphics along with text in their communications, they function best when networked, and they often engage in multi-tasking. They prefer games and trial and error approaches for solving problems. They learn best when actively doing rather than watching. Moreover, they like collaborative teamwork when completing tasks.

The current challenge for teachers is to not only recognise the differences in how students come to the learning table, but to also recognise the skills they need for effectively engaging in the tasks of a more global society. The Partnership for 21st Century Learning (2015) and the Thoughtful Learning Organization (2016) both draw attention to the 4C's as learning and innovation skills for successful citizenship in a global society: critical thinking, creative thinking, communicating, and collaborating. They claim that these skills help students learn to engage in today's more complex social, cultural, and educational environments integrated with the multiple technological resources of the twenty-first century.

Through the 4C's, students are able to take advantage of various thinking and engagement strategies:

- In critical thinking they rely on analytic thinking as they engage in problem solving where they make comparisons, contrast, analyse, categorise, and evaluate.

- In creative thinking they engage in open-ended invention and discovery of myriad solution possibilities where they design, improvise, innovate, problem solve and ask questions.

- In communication they interact with others, where they connect via multiple modes (e.g., text, social media, cell phones, email, Internet and other avenues). Through their communications, they engage in analytic and communication tasks where they think about the subject, purpose, sender, receiver, medium and the context of the messages. They must listen actively, follow conventions, decode written words and images, take turns, and use technology appropriately. 
- In collaboration they work together toward a common goal. Typically, this action involves brainstorming ideas, making decisions as a group, delegating, evaluating, goal setting, managing time, resolving conflicts, and team building. Leaders in these collaborative groups create environments where all members contribute according to their ability and participate in the collaborative decision-making.

In support of these skills, ISTE (2016) now proposes seven new student standards for the enhanced digital world. Students, through the use multiple digital technologies, engage as: (1) empowered learners, (2) digital citizens, (3) knowledge constructors, (4) innovative designers, (5) computational thinkers, (6) creative communicators, and (7) global collaborators.

Teachers now must identify, orchestrate, and manage the learning tasks in the content areas in a manner that supports their students in engaging in these critical learning skills in knowledge building communities to take advantage of the power of technologies as learning tools. This challenge involves far more than teachers' understanding of their content. It ultimately challenges their technological pedagogical reasoning as well as their knowledge for teaching with a vast array of technological innovations. In other words, "Quality teaching requires developing a nuanced understanding of the complex relationship [among technology, content, and pedagogy], and using this understanding to develop appropriate, context-specific strategies and representations” (Mishra \& Koehler, 2006, p. 1029).

The demand for such a nuanced understanding introduces this question: On what is the professional knowledge base of teaching for more thoughtful teaching and learning in the twenty-first century built? Responding to this question points to technological pedagogical content knowledge (TPACK) (Angeli \& Valanides, 2005; Mishra \& Koehler, 2006; Niess, 2005) as a foundation supporting such knowledge building. With a firm theoretical grounding for describing the relationship among technology, pedagogy, and content knowledge, the question shifts to building knowledge of how teachers' pedagogical reasoning and actions are developed when engaging technology as a learning tool.

Recognising that technologies are optimised for a particular use or function and responding to the ISTE standards for using multiple technologies, it is important that teachers employ multiple technologies in concert to support learning goals and objectives (Gillow-Wiles \& Niess, 2014). For example, technology designed for enhancing inquiry-based learning (e.g., graphing calculators) can be paired with technology best suited for sharing student thinking (e.g., computer/projector or document camera) to support collaboration and reflection, leading toward deeper, higher level thinking. Since each of these technologies supports only part of the learning experience, knowing how they interact and how best to integrate them is an important pedagogical aspect of a teachers’ TPACK (Niess \& Gillow-Wiles, 2013).

The burgeoning landscape of available technologies for use in the classroom creates another aspect of TPACK, that of a systems pedagogical approach. Teachers must develop knowledge that encompasses how to choose the most appropriate technology for a particular aspect of a learning experience and how best to holistically integrate multiple technologies into a dynamic and complete package where each aspect of learning is attended to and completely supported (Niess \& Gillow-Wiles, 2013). The emerging need for teachers to integrate more than a single technology into teaching and learning spaces increases the demands on teacher preparation programs at the tertiary level, to design experiences that guide both pre-service and in-service teachers in developing and enhancing their technological pedagogical reasoning and, thus, supporting their TPACK development.

Through using a system of technology approach in developing TPACK, it is argued that technology becomes a pedagogical tool, where the group of technologies, engaged in concert, combine to support the development of the transformative knowledge at the core of TPACK (Gillow-Wiles \& Niess, 2014). From this standpoint, the critical question focusing this investigation centers on how the teachers' technological pedagogical reasoning is influenced through engagement of a system of multiple technologies as pedagogical tools and using the 4C's to guide the design of learning and innovation skills development for successful citizenship in a global society.

\section{Expanding pedagogical reasoning to technological pedagogical reasoning}

In the 1990's, the predominant perspective on teachers' pedagogical reasoning rested within a merging of 
content and pedagogical knowledge bases as they reasoned in ways that transformed their content into content meaningful for their students. This understanding focused on helping teachers make important connections for their students, beginning with comprehension of the subject matter and continuing with new comprehension after reflection on the instruction (Wilson, Shulman, \& Richert, 1987). No mention of the influence of technological tools was directly considered when thinking about pedagogical reasoning at this time.

Yet, when considering teachers’ pedagogical knowledge, Mishra and Koehler (2006) claimed, “The leap of faith, however, is that by demonstrating their proficiency with current software and hardware, teachers will be able to successfully incorporate technology into their classrooms” (p. 1031). With increased access to multiple technologies, the pedagogical challenge shifts to developing an understanding of the influence of multiple technologies on teachers' pedagogical reasoning. Thus, the task for teacher educators then shifts toward building a pedagogical reasoning that integrates technologies as teaching and learning tools.

The influence of multiple technologies on teachers' pedagogical reasoning requires a more advanced pedagogical understanding of the interaction among content, technology, and pedagogy. In TPACK, teachers merge the three knowledge bases as they work to transform the content, as they know it, into content meaningful for their students while using technological learning tools. With this understanding, teachers must develop a pedagogical reasoning process that makes valid and important connections with multiple technologies for the students as they are learning, beginning with comprehension of the subject matter and continuing with new comprehension after reflection on the instruction - a technological pedagogical reasoning process. The transformation of knowledge that incorporates technologies into a form accessible to the learners is at the center of the enhancement of teachers' TPACK and the technological pedagogical reasoning process as more and more technologies present affordances as learning tools.

Building on the work of Wilson et al., Starkey (2010) posits a new conceptualisation of pedagogical reasoning where technologies are integrated into the curriculum as teaching and learning tools. An important aspect of this research is the development of a model of teachers' pedagogical reasoning and action for the digital age, where technology plays a critical role in building knowledge. In this model, Starkey identifies criteria in a cyclical trajectory through which teachers build knowledge in building their understanding:

- comprehension of subject (content knowledge)

- $\quad$ enabling connections (preparation for teaching)

- teaching and learning (knowledge of context)

- reflection (review and critical analysis)

- $\quad$ new comprehension (about the subject, students, and teaching)

These criteria provide an avenue to evaluate how teachers use technology in their teaching and learning, bring light to an understanding of their TPACK and are useful in this research. In essence then, the selection of the Starkey (2010) model provides a foundational element over the Wilson et al. (1987) model by focusing on pedagogical reasoning in a technology-rich teaching and learning environment - a technological pedagogical reasoning process.

\section{A systems technological pedagogical reasoning process}

The current teacher knowledge challenge is to identify and describe a twenty-first century technological pedagogical reasoning process that incorporates multiple technologies. Each new technology is designed for particular applications; yet, through careful consideration, the technology might also be used in concert with other technologies to support communication, collaboration and inquiry learning experiences. Basically, teachers must consider multiple technologies with the intent of supporting specific instructional goals. What makes this process a system is that the teacher's reasoning results in a unified whole or a group of interacting experiences that ultimately result in communication, collaboration and inquiry experiences and learning. 
Consider this example. Temperature probes might be incorporated as inquiry tools to support students in dynamically exploring a particular temperature phenomenon such as the temperature of ice as it melts and then boils. This tool supports students in preparing a graphical representation of the data for describing the change throughout the process. After becoming familiar with the probe, students collect additional temperature data as baking soda is added to vinegar to examine an active reaction. Is there a temperature change as the two are mixed and if so how does the temperature change? After gathering the temperature data and creating a graphical presentation, students individually rely on video software as a communication tool to share their analyses of the reaction using the data and spreadsheet graphical representations. Finally, a small group of students uses Google Docs as a collaborative tool to develop a cooperatively-designed essay as they discuss their results and explain how and why the temperature changes as it does at particular points on the graphs.

The dynamic interplay, as illustrated in Figure 1, displays how these different technologies provide participants with the tools they need for inquiry, communication/sharing, and collaboration (Gillow-Wiles \& Niess, 2014). As the participants smoothly transition from one technology use category to another, they are able to direct their own learning, engage with the community of learners, and develop shared and individual knowledge (Akyol \& Garrison, 2008). It is in the intersection of these use categories where the most impact exists for developing the teacher's systems knowledge for teaching and learning with multiple technologies (Kim, Kim, Lee, Spector, \& DeMeester, 2013).

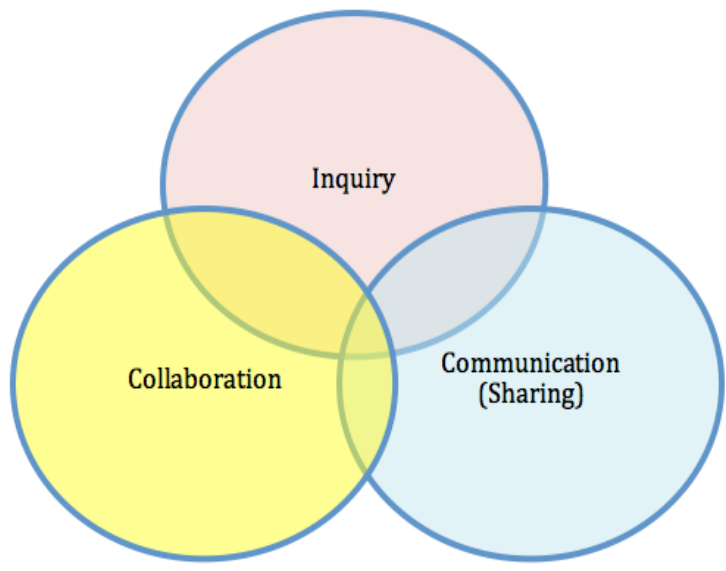

Figure 1. Interaction model of technology usage categories

In this framework, the interactive relationship between these technology usage categories is developed through a systematically conceptualised holistic integration of multiple technologies, each chosen to support a particular instructional goal. The culmination of instructor technology choices focusing on supporting educational goals lies at the intersection of the technology usage categories, where the different technologies merge into a system of technologies (a technological system).

Orchestrating these experiences requires teacher engagement in a reasoning process that recognises the implications of the multiple technologies on student learning. This imperative is reflected in the 2016 ISTE Student Standards and Starkey's (2010) model for pedagogical reasoning and action for the digital age. Teachers engage in a reasoning process that resembles a systems reasoning approach when attending to the impact of the multiple technologies when used for different purposes (Gillow-Wiles \& Niess, 2014). Such a systems approach attends to the challenges of organising and supporting students in inquiry, communication and collaboration in ways that take advantage of the technological affordances collectively for learning engagement.

Consider this dictionary definition of the word system: "a regularly interacting or interdependent group of items forming a unified whole or a group of interacting bodies under the influence of related forces" (Merriam-Webster, 1999). This group of interacting items (different technologies) is under the influence of related forces (the needs of the educational context) where each technology provides support for part of the instructional strategy choices and/or educational goals. When technologies are used in concert (a unified whole), they become a system of technologies where the whole is greater than the sum of the parts (Gillow-Wiles \& Niess, 2014). 
Through this action, this systems process becomes a pedagogical tool, “a tool that mediates a teacher's action, proving clear and detailed principles regarding learning that can be easily translated into teaching practice. Pedagogical tools therefore not only make links between theory and practice, they help teachers move from the potentially abstract to the concrete" (Seale \& Cooper, 2010, p. 1110). A systems technological pedagogical reasoning and thinking is important when purposefully planning to guide students' skills and understandings of which technologies to use and for what educational purposes.

The 4C's as learning and innovation skills educational goals align well with the systems technological pedagogical reasoning for making technology choices and orchestrating their integration in instruction. Essentially, teachers' technological pedagogical thinking and reasoning results in the use of a combination of multiple technologies, forming a system of learning with technologies. Throughout a systems technological pedagogical reasoning process for integrating technology in the classroom, teachers consider engaging students in inquiries that involve them in communicating and collaborating while engaged in critical thinking and creative thinking. The greatest impact of this systems process is student engagement in ways that require a consciously planned combination of multiple thinking strategies such as creative thinking and critical thinking. However, the challenge remains for determining how teachers develop a systems technological pedagogical reasoning process.

\section{Developing teachers' technological pedagogical reasoning}

Although pedagogical knowledge and reasoning are considered central to a teacher's knowledge (Putnam \& Borko, 1997; Shulman, 1987), they have rarely been investigated in relationship to technology. In fact, according to Krauskopf, Zahn, and Hesse (2012), how teachers' pedagogical knowledge relates to their understanding of the affordances of technology remains a question to be examined. Our study focuses on describing how a systems pedagogical approach influences teachers' technological pedagogical reasoning when integrating multiple technologies as learning tools.

Teachers need experiences that confront their current pedagogical conceptions for integrating technologies as learning tools in their content areas (Loughran, 2002); they need to reframe their pedagogical understandings in ways that support interactivity among their students as they take advantage of specialised affordances of multiple technologies for communication, collaboration and inquiry. Teachers need educational experiences about and with the new technologies blended with models of how the various technologies enhance learning of the content as well as what pedagogical strategies are helpful for actively engaging students in knowledge building communities where they communicate and collaborate as they are also engaged in inquiry that requires critical thinking and creative thinking.

Designing teachers' dynamic learning experiences about and within the systems approach for integrating technologies suggests the experiences be framed in socio-metacognitive-constructivist learning experiences (Niess \& Gillow-Wiles, 2013). Such experiences engage the teacher participants as a community, collaborating about their explorations, research, and reflections about their own experiences for connecting with students' thinking about and learning with technologies. This learning trajectory consistently engages them in thinking and reflecting about the dynamic interactions among content, pedagogy and technology emerging from the tasks in which they are engaged (Roberts, 2002; Wheatley, 1992).

Knowledge building (Scardamalia \& Bereiter, 1993) experiences involve the process of "working toward a more complete and coherent understanding" (p. 39). In this perspective, knowledge building is a "social activity, with new information and ideas brought in the discourses of a community that shares goals for knowledge advancement and recognizes contribution” (p. 39). Such educational experiences have potential for engaging their technological pedagogical reasoning and action, as more and more technologies are available as educational tools.

In addition, Krauskopf et al. (2012) suggest that teachers need opportunities to develop mental models (Johnson-Laird, 1980; Westbrook, 2006) that are "more situated and specific than general beliefs or declarative knowledge about technologies” (p. 1195). Ultimately, these learning experiences effectively reframe their pedagogical knowledge. With respect to increasing the availability of more technologies, Krauskopf et al. (2012) suggest, "Complete mental models are indicators for a deep understanding of 
complex systems” (p. 1195). The transformation of knowledge as described by TPACK's center intersection proposes such "a mental model representation of elements and interrelations that can be manipulated and from which inferences can be made (p. 1196).

Harris, Mishra, and Koehler (2009) extend the notion of mental models as being developed through "a pedagogically focused approach" using learning activities that emphasise "the differences among learning activities in different content areas rather than their similarities” (p. 403). With this pedagogically focused approach, the learning activity types provide a "nontechnocentric approach” (Harris et al., 2009, p. 405).

There is significant alignment between the necessary elements for developing effective mental models and teacher pedagogical reasoning and action for the digital age (Starkey, 2010). Krauskopf et al. (2012) add that the ideas necessary for teachers' professional development content include the consideration of:

- Cognitive functions that refer to a student's individual learning and how he or she deals with the transformation presented in the learning material and tasks. This concept aligns with the Enabling Connections (adapting/tailoring learning for the students being taught) component of the Starkey (2010) model.

- Socio-cognitive functions that refer to collaborative learning settings where knowledge and activities are distributed over several learners as they exchange, negotiate meaning and build new knowledge. This concept aligns with the Enabling Connections (enabling connections between groups and individuals to develop knowledge) component of the Starkey model.

- Metacognitive aspects that involve actual regulation of the learning process. This concept aligns with the Teaching and Learning (evaluations of student learning with feedback to the students) component of the Starkey model.

- Motivation that is concerned with the technology as incentive for gathering the learners' interest. This concept aligns with the Enabling Connections (selecting appropriate resources and methods to enable students to make connections with prior knowledge) component of the Starkey (2010) model.

As more of these aspects are involved in teachers' professional development experiences, a more complex mental model potentially evolves that "enables teachers to create better solutions to a TPACK task, namely the planning of a lesson that leverages the affordance of the technology” (Krauskopf et al., 2012, p. 1197).

In combining the model of teacher pedagogical reasoning and action for the digital age (Starkey, 2010) with the 4C's developed by the Partnership for $21^{\text {st }}$ Century Learning (2015) and the 2016 ISTE Student standards as a pedagogical foundation for course design, the research effort identified alignment between the various models and standards, and the systems technological pedagogical reasoning approach being developed in this research. For example, the reflection component of the Starkey model focuses on review and critical analysis to develop knowledge. This concept is found in the ISTE (2016) Student Standards where students need to be knowledge constructors, and in the 4C's standard for critical thinking. Similar alignments can be found with other aspects of these models.

\section{The study}

With these understandings, our research effort focused on teachers' development of a more complex mental model for teaching with technologies, specifically enhancing teachers' pedagogical reasoning through a systems pedagogical approach when integrating multiple technologies in their classroom teaching. Our primary research question was: What is the influence of systems thinking on teachers' pedagogical reasoning with technologies to integrate and interweave inquiry, communication and collaboration as revealed through their classroom teaching?

This research effort engaged the multiple models (Harris et al., 2009; Krauskopf et al., 2012; Scardamalia et al., 1993; Starkey, 2010) in concert to create a foundation on which we constructed the proposed systems pedagogical reasoning model. Beginning with these existing models, we extended the concept to describe how multiple technologies might be holistically integrated to become more than a simple combination of technologies, resulting in a self-contained pedagogical tool in its own right. Building on the existing models of teacher pedagogical reasoning and action, this new, systems-based approach 
guided the direction of the development of the research questions and design. In designing the courses at the focus of the research, we engaged both the Starkey (2010) model trajectory and the systems pedagogical reasoning model as a framework for creating units where the lesson arc followed the cyclic path of the Starkey model. Additionally, the criteria found in the teacher pedagogical reasoning and action model (Starkey, 2010) were used to guide the description of teachers' TPACK around their thinking about the role of a system-of-technology pedagogical tool in their teaching.

A 3-year, online Masters of Science (MS) program in Mathematics Education provided the context for examining this question. An online TPACK learning trajectory based on a socio-metacognitiveconstructivist framework (Niess \& Gillow-Wiles, 2013) guided the design of the online courses in the MS program. Each course incorporated two key tools: (1) a community of learners and (2) consistent incorporation of reflection. Two processes were empowered through these tools: (1) valuing and building upon shared and individual knowledge and (2) active inquiries throughout the scaffolding of the content in the courses.

The researchers used a design-based research approach (Niess \& Gillow-Wiles, 2014) over a 2-year period to develop two technology-enhanced courses for engaging the teacher-participants in learning experiences with multiple technologies, scaffolding their learning experiences using a systems pedagogical approach. With the challenge of integrating more and more technologies as learning tools in ways that also engage students in the 4C's, the courses focused on guiding the participants in developing the pedagogical understanding for making decisions as to which technologies should be integrated with which content, for which learning purposes and how best to orchestrate the learning. Thus, the coursework guided their learning about teaching with multiple technologies and the pedagogical strategies guided their learning about the technologies as well as developing their pedagogical understandings for teaching with these technologies. The systems pedagogical approach highlighted the work in these two courses with multiple technologies for learning using critical thinking, creative thinking, communication and collaboration (the 4C's) along with the online tools and processes.

The primary goal for each of these courses was to develop the pedagogical understanding needed to make decisions as to which technologies should be integrated with which content, for which learning purposes, and how best to orchestrate the learning. The scaffolding of the content focused on developing and extending their understandings and skills with multimedia technologies with the intent of engaging the teachers as students in ways where they explored the technological features and capabilities, where they considered how the technologies were supportive of students' learning in mathematics. Table 1 summarises the content, technologies, and pedagogies that were interwoven in both of these courses (SED 521 and SED 520), demonstrating the reliance on multiple technologies along with specific communication, collaboration and inquiry-type pedagogically organised tasks (engaging, exploring explaining, elaborating, evaluating, acquiring, analysing, creating, communicating).

According to Shulman (1987), pedagogical reasoning is developed "through the process of planning, teaching, adapting the instruction, and reflecting on the classroom experiences” (p. 117). From Starkey (2010) pedagogical content knowledge in the digital age includes "knowledge of the subject including content, approaches and perspectives, and knowledge of how to teach the subject so that students are able to create and critique knowledge through connections” (p. 239). The challenge was then to design another course where the teachers had an opportunity to practice their understandings. Therefore, the program design identified a third course (SED 594) to follow these two courses with which to involve the participants in designing, implementing, analysing, and reflecting on teaching and learning in a 5-day sequence of lessons that integrated technologies as learning tools in their classrooms. 
Table 1

Primary content, technologies and pedagogies incorporated into two technology-enhanced courses

\begin{tabular}{|c|c|c|}
\hline \multicolumn{3}{|c|}{ Teaching Mathematics and Science with Digital and Video Technologies (SED 521) } \\
\hline Primary Content & Technologies & Pedagogies \\
\hline $\begin{array}{l}\text { Teaching and learning } \\
\text { with digital images }\end{array}$ & $\begin{array}{l}\text { Digital images } \\
\text { Spreadsheet } \\
\text { PowerPoint } \\
\text { Jing screen capture } \\
\text { Gimp } \\
\text { Word }\end{array}$ & $\begin{array}{l}\text { Inquiry: Acquire, Analyse, Explore, Create } \\
\text { Communicate: Explain, Elaborate } \\
\text { Collaborate: Analyse, Explore, Explain, } \\
\text { Elaborate } \\
\text { Reflection }\end{array}$ \\
\hline $\begin{array}{l}\text { Teaching and learning } \\
\text { with videos }\end{array}$ & $\begin{array}{l}\text { Videos } \\
\text { Spreadsheet } \\
\text { PowerPoint } \\
\text { Jing screen capture } \\
\text { Movie Maker, iMovie } \\
\text { Word }\end{array}$ & $\begin{array}{l}\text { Inquiry: Acquire, Analyse, Explore, Create } \\
\text { Communicate: Explain, Elaborate } \\
\text { Collaborate: Analyse, Explore, Explain, } \\
\text { Elaborate Evaluate } \\
\text { Reflection }\end{array}$ \\
\hline \multicolumn{3}{|c|}{ Integrating Technology \& Literacy in Learning Mathematics and Science (SED 520) } \\
\hline Primary content & Technologies & Pedagogies \\
\hline $\begin{array}{l}\text { Twenty-first century } \\
\text { literacy }\end{array}$ & $\begin{array}{l}\text { Google slides } \\
\text { PowerPoint } \\
\text { Jing screen capture }\end{array}$ & $\begin{array}{l}\text { Inquiry: engage, explore } \\
\text { Communicate: analyse, explain } \\
\text { Collaborate: explore, elaborate, explain } \\
\text { Reflect }\end{array}$ \\
\hline $\begin{array}{l}\text { Higher order thinking } \\
\text { with probeware }\end{array}$ & $\begin{array}{l}\text { Temperature probe } \\
\text { PowerPoint } \\
\text { Jing screen capture } \\
\text { Word }\end{array}$ & $\begin{array}{l}\text { Inquiry: engage, explore, explain } \\
\text { Communicate: explain } \\
\text { Collaborate: explore, analyse, elaborate } \\
\text { Reflect }\end{array}$ \\
\hline Web Inquiry & $\begin{array}{l}\text { Web inquiry template } \\
\text { Google Docs } \\
\text { Google Sites } \\
\text { Word }\end{array}$ & $\begin{array}{l}\text { Inquiry: engage, explore, create } \\
\text { Communicate: analyse, explain, elaborate } \\
\text { Collaborate: explore, create } \\
\text { Reflect }\end{array}$ \\
\hline Individual applications & $\begin{array}{l}\text { Web applications } \\
\text { iPad applications } \\
\text { Word }\end{array}$ & $\begin{array}{l}\text { Inquiry: explore, create, explain } \\
\text { Reflect }\end{array}$ \\
\hline $\begin{array}{l}\text { SWOT (strengths, } \\
\text { weaknesses, } \\
\text { opportunities and } \\
\text { threats) analysis }\end{array}$ & $\begin{array}{l}\text { Google Docs } \\
\text { Word }\end{array}$ & $\begin{array}{l}\text { Inquiry: analyse, explain } \\
\text { Communicate: explore, elaborate } \\
\text { Collaborate: explore, analyse, explain, } \\
\text { Elaborate, evaluate } \\
\text { Reflect }\end{array}$ \\
\hline
\end{tabular}

In this third course, the participants developed electronic portfolios following guidelines for the development of a "Notebook" (Borko, Stecher, \& Kuffner, 2007) or electronic portfolio. Table 2 describes the expectations the teachers needed to complete and present through their electronic notebooks by the end of the course. As the participants collaborated in the online portion of the course about various instructional strategies for teaching with technologies, they gathered multiple artifacts, representing their action as they designed, implemented, analysed and reflected on teaching with technologies in their classrooms.

This SED 594 course focused the participants in gathering artifacts from their designed sequence of lessons (reflecting daily and cumulatively on the instruction in their own mathematics classes). Throughout this experience, they used two reflective thought processes (reflection-in-action and reflection-on action) (Schön, 1983). They videotaped, analysed, and reflected on two lessons while also reflecting on their instruction and their students' interactions and submitted work. They peer reviewed another participant's collection and received another peer's views on their own collection. Then, they completed a final assessment and reflection to refine their electronic portfolio collections so that the artifacts more accurately reflected the thinking and reasoning about teaching and learning with technologies. Throughout the process, they relied on their personal mental models as they thought about incorporating the affordances of multiple technologies as teaching and learning mathematical tools to support students in communication, collaboration, critical thinking and creative thinking. 
Table 2

Electronic portfolio expectations as teachers designed, implemented, analysed, and reflected on teaching and learning in their classrooms

1. Electronic portfolio collection:

a. Project overview including Introduction and Table of Contents

b. Overall portfolio description

c. Daily lessons:

i. Daily calendar

ii. Daily lesson plans

iii. Summary, analysis and assessment of artifacts for at least 3 lessons

d. Lesson Reflections:

i. Pre-lesson reflection questions

ii. Daily reflection questions

iii. Post lesson reflection questions

e. Supporting documents:

i. Video analyses:

1) Video 1 analysis

2) Video 2 analysis

3) Video analysis, survey, and reflection

ii. Photograph log

iii. Daily supporting documents

iv. Daily instructional materials

v. Artifacts documenting learning (such as copies of student work) analyses

2. Partner assessment and recommendations:

a. Overview

b. Single "lesson observation" ratings for the two video lesson analyses

c. Summary rating for entire collection of lessons: These two sections provide the rate scales and the information that describes them:

i. Mathematics dimensions

ii. Mathematics rating scale

d. Recommendations for improving the collection

3. Final portfolio reflection and synthesis on technology-enhanced mathematics teaching and learning:

a. Reflection on refinement of electronic portfolio collection

b. Final analysis and reflection

\section{Data sources and analysis}

The final electronic portfolios provided the primary data sources for this descriptive study. Starkey's (2010) model of teacher's pedagogical reasoning and action for the digital age framed the analysis of the electronic portfolios. However, since we were primarily interested in the influence of the systems pedagogical approach for working with multiple technologies, we adapted the wording for clarity of intent in the analysis. Table 3 further describes the five primary criteria in Starkey's model with our adaptations in italics and how we used the electronic portfolio data in our analysis. The bulleted arrows identify data sources for conducting the analysis in each section of the Starkey adapted model. This model created a more contextually appropriate analysis framework for guiding our analysis. 
Table 3

Starkey's five primary criteria outlining the electronic portfolio data sources for analysing the participants' pedagogical reasoning and actions for the digital age

\begin{tabular}{|l|l|}
\hline Digital age pedagogical reasoning and actions & Electronic portfolio data sources
\end{tabular}

I. Comprehension of the subject (technological content knowledge) when integrating technologies in subject matter topics:

- $\quad$ Substantive knowledge (concepts and principles when integrating technologies)

- $\quad$ Syntactic knowledge (subject methodologies when integrating technologies)

- $\quad$ Daily lesson plans

- $\quad$ Pre, daily and post lesson reflections

- Summary analysis and reflection on videos

- Peer review assessment and recommendations

- Summary analysis and assessment of artifacts

II. Enabling connections - Preparation for teaching with technologies (technological pedagogical content knowledge)

- $\quad$ Selecting appropriate resources to enable students to make connections between prior knowledge and developing subject knowledge with technologies

- $\quad$ Transforming existing knowledge into teachable content with technologies

- Enabling opportunities for students to create, critique and share knowledge with technologies

- $\quad$ Enabling connections between groups and individuals to develop knowledge of the subject when using technologies

- $\quad$ Adaptation and tailoring (personalising) learning for the students when using technologies

III. Teaching and learning with technologies (knowledge of context as represented by pedagogical content knowledge)

- $\quad$ Formative and summative evaluations of student learning with technologies with feedback to students (from a variety of sources)

- Modification of the teaching process when teaching with multiple technologies where appropriate

- $\quad$ Daily lesson plans

- $\quad$ Pre, daily and post lesson reflections

- Video analysis survey and reflection

- Summary analysis and reflection on videos

- Peer review assessment and recommendations

IV. Reflection on teaching and learning with technologies (TPACK)

- $\quad$ Reviewing and critically analysing teaching decisions when integrating technologies based on evidence

- $\quad$ Pre, daily and post lesson reflections

- Video analysis survey and reflection

- Summary analysis and reflection on videos

- Reflections on student artifacts

- Final analysis and reflection

V. New comprehensions on TPACK and teaching with technologies considering:

- $\quad$ Subject matter

- Students

- Teaching

- $\quad$ Post lesson reflections

- Video analysis survey and reflection

- Summary analysis and reflection on videos

- Summary analysis and assessment of artifacts

- Reflections on student artifacts

- $\quad$ Final analysis and reflection

In this qualitative study, we independently analysed each teacher's electronic portfolio to capture each participant's progression and outcomes from the portfolio experiences (Myers, Chappell, Elder, Geist, \& Schwidder, 2003). Since the focus of this study was the influence of the experiences on the systems thinking of teachers' pedagogical reasoning with technologies to integrate and interweave inquiry, communication and collaboration as revealed through their classroom teaching, the coding processes were analysed with respect to Starkey's adapted model (Table 3). We used the specific artifacts in the portfolios (as described in Table 3) in the process of presenting each teacher's pedagogical reasoning and 
action. Meyer's (2001) work guided the choice for descriptive cases, where the logic of case-study sampling was differentiated from that of statistical sampling; the qualitative sampling sought "information richness ... selecting cases purposefully rather than randomly" (p. 333). The seven cases illustrated the participants' experiences for completely describing the mental models revealed through each participant's experiences in the electronic portfolio process and how that process impacted the thinking (Curtis, Gesler, Smith, \& Washburn, 2000). To create this description of each participant's progression and outcomes from the electronic portfolio experiences, each researcher separately completed in-depth examinations of each of the seven electronic portfolios to portray the teachers' technological pedagogical reasoning and action as displayed through the Starkey adapted model (Table 3) from their electronic portfolio experiences.

Using a multi-cycle coding process, the electronic portfolio data were analysed to reveal underlying themes for describing how each participant's thinking was affected by the electronic portfolio experiences. The first coding cycle employed an attribute coding process (Saldana, 2009), where data from all sources for each criterion (see Table 3) were examined for participant information and contexts for analysis and interpretation. This coding type provided a grand tour of the data and provided a comprehensive overview of what was collected. Additionally, this coding process resulted in the recognition of preliminary patterns and themes that bore further investigation in the second coding cycle. The first coding cycle produced a large number of representative phrases for describing the thinking of the participants or representing their actions toward portraying a mental model of their reasoning and thinking. These phrases were coded into a number of code categories: for example, what the participants were referring to when considering which technologies should be integrated with which content; what instructional strategies to use with the technologies; for what learning purposes were the technologies being integrated; and how best to orchestrate the learning. As the process continued, a number of codes were collapsed (e.g., the various instructional strategies codes became a single category called instructional strategies).

The second coding cycle employed a pattern coding process (Saldana, 2009), where the coding process pulled together a variety of material into more meaningful units of analysis, revealing a "smaller number of sets, themes, or constructs" (p. 152). Now, the specific artifacts in the notebooks were considered with respect to each teacher's pedagogical reasoning and action as displayed in Starkey's adapted model (Table 3). For example, with respect to the criterion about the participant's thinking about teaching and learning with technologies (i.e., their TPACK), multiple reflections throughout the electronic portfolio process were used to identify the participant's reasoning and action.

The pre-lesson, daily lesson, and post lesson reflections provided a preliminary view of the participants' progressive thinking about the keys to teaching and learning with technologies. At this point, one participant was focused on time management when her students were working with the technologies; here this participant claimed time management to be her "biggest instructional issue" for teaching and learning with technology. Yet, her reflections on the videos and student artifacts showed her thinking shifted to a concern for instruction that better supports students in understanding the topics when learning with technologies. By the final analysis and reflection, this participant identified her primary concern for teaching and learning with technology as the need "to incorporate more problem-solving opportunities for my students so that they can be more engaged in applying the skills and concepts we are learning." In essence, her reflections over the course of the electronic portfolio reflective process shifted from time management to the importance of problem-solving when thinking about teaching and learning with technology.

The use of multiple data sources obtained over a period of time helped to capture the more in-depth thinking and reasoning about teaching and learning with technology. Each independent analysis by the researchers identified general patterns with respect to each teacher's pedagogically focused mental model through the planning, implementation and multiple reflections in the electronic portfolio process that involved integrating technologies throughout the five instructional lessons.

Thus, the use of multiple data sources helped to capture more in-depth thinking and reasoning about teaching and learning with technology. Each of our independent analyses identified patterns and themes in the planning, implementation and multiple reflections throughout the electronic portfolio process with respect to each participant's thinking and reasoning for teaching with multiple technologies throughout 
the five instructional lessons. We used these patterns and themes for each participant and framed an agreed-upon mental model for each participant's pedagogical understanding and reasoning. If we each proposed different descriptions, we reviewed the data sources until we agreed on a description. Through this process, we identified descriptive quotes that more fully described the mental model for each participant.

Once the mental models were confirmed, we collectively worked at identifying and validating cross case themes from the multiple case descriptions of the mental models of pedagogical reasoning and understandings. With each theme, we identified representative quotes. Through this process, the accumulation and cross case analyses documented the influence of the systems pedagogical approach on the teachers' technological pedagogical reasoning and action with multiple technologies as revealed through their electronic portfolios.

\section{A representative case}

The MS program is an online program for K-12 in-service teachers to develop their thinking, knowledge and skills for engaging their students as critical thinkers and creative producers of knowledge and understandings in teaching and learning mathematics. The scaffolding of the content for each course throughout the program focused on establishing and extending their understandings and skills with multimedia technologies and for teaching with multiple technologies in concert with other materials.

Seven teachers participated in the research on the electronic portfolio course (SED 594). Three of the teachers had previously taken both of the technology-enhanced courses (SED 520 and SED 521) prior to taking the electronic portfolio course. Three others had taken SED 521 before taking the electronic portfolio course while the final participant had completed only the SED 520 prior to taking the electronic portfolio course. While we were able to complete the case analyses of all seven teachers, the analyses of the three participants' pedagogical reasoning and actions who had taken both SED 520 and SED 521 prior to the electronic portfolio class provided a clearer description of the influence of the technological systems pedagogical approach.

This representative case (Lindsey) provides specific details concerning the influence of the systems technological pedagogical approach. The analysis of Lindsey's mental model of pedagogical reasoning and action used Starkey's adapted model with the specific criteria and Starkey number bolded in the text along with representative quotes from her electronic portfolio. The cross-case analysis follows this descriptive case, presenting the key themes and patterns that evolved concerning the influence of the systems pedagogical approach as viewed through all seven teachers’ electronic portfolios.

\section{Lindsey}

Lindsey is a secondary mathematics teacher who taught more than 10 years in a rural high school. A computer, Smart Board, and graphing calculators were common technologies used in her mathematics classes to support students in exploring mathematical concepts and processes. In the MS program, Lindsey was excited about taking the two technology-based courses, hoping to develop her knowledge for incorporating additional technologies in her instruction. The electronic portfolio class provided her with an opportunity to examine her teaching in her own classroom and how multiple technologies might be incorporated to support students' learning of mathematics.

Lindsey's mathematical content knowledge and understanding were well established through her undergraduate mathematics coursework and her teacher preparation courses. Her strong background in mathematics provided her with the ability to teach a broad range of mathematics at the high school level, including algebra 1 and 2, geometry, trigonometry, pre-calculus and calculus. With respect to her comprehension of the subject (Starkey I), she not only had substantive knowledge of concepts and principles for these multiple mathematics courses. Her knowledge was well-aligned with the national and state core standards, the national mathematics teacher standards and the ISTE Student standards. Her mathematics background also assured depth in her computational and syntactic knowledge for teaching in high school as well as for identifying appropriate uses of technologies in building mathematical knowledge. 
She decided to use her pre-calculus class and a unit on exponential, logarithmic, and logistic curves for the electronic portfolio lessons because the students had previously taken a computer applications course that she assumed would provide the necessary skills for adding new technologies for students to gather data for examining specific mathematical curves. For the electronic portfolio instruction she planned to include familiar classroom technologies (Smart Board, graphing calculators, computers, Word, Excel and the Internet). After her experiences with probeware, such as Vernier Go! Temperature Probe and the Logger Lite software, in SED 520, she made the decision to add them to her classroom technologies. She also wanted to use the $\mathrm{pH}$ probe but the school did not have access to it. Instead, she used $\mathrm{pH}$ paper to have the students examine the differences in the technologies for gathering and describing acidic and alkaline solutions. Lindsey completed all the electronic portfolio expectations using this class and the multiple technologies. However, she did switch classrooms with the science teacher in order to provide students with the appropriate lab materials and space as they conducted their experiments and gather the necessary data. She admitted that with the incorporation of these science experiments, she "had to face the student's acceptance to doing 'science' in math class." She demonstrated her substantive knowledge and syntactic knowledge (Starkey I) indicating how she focused her students by providing "real life" to the data they were graphically analysing in this math class, indicating "students made connections among the mathematics functions as well as science topics."

Lindsey recognised that she would need to provide opportunities for the students to learn how to work with these technologies. She selected similar activities to those that she had used when she was in SED 520. She identified and orchestrated a variety of enabling connections (Starkey II) that considered cognitive functions, socio-cognitive functions, motivational functions and meta-cognitive functions in her reflections on her preparation for teaching to incorporate the probeware to model logistic curves. Examples of these different technological functions identified in her thinking included:

- Cognitive function: "I remembered this summer I used the Go!Temp Thermometer to measure the temperature of ice as it melted and then boiled. The shape of the data resembled a logistic curve. I used that to connect logistic curves to real life.”

- Motivational: "I was also able to incorporate an Internet activity/project, in which students gathered data on different populations - a real life exponential decay or growth activity.”

- Socio-cognitive, motivational and metacognitive: "I incorporated whole group and small group discussions, discovery learning, scaffolding, and real-world application.” For the tape dust activity: "Students will pair up and share their answers to the lab from yesterday. As groups finish, I will select a few to present their answers to the whole class. This will transition from a partner discussion to a large group discussion. After the discussion, students will collect data from their tape and record and reflect on their results.”

For the teaching and learning (Starkey III) she incorporated "cooperative learning, group work, discussions, brainstorming, hands-on activities, and guided practice." She planned to assess the effectiveness of these strategies through personal observation, video analyses, artifacts and homework assessments. The introductory activity involved students in a brainstorming activity to identify a list of real-world applications of the three functional curves in this unit. They used a Venn diagram to find the similarities and differences of the curves. Students used their smart phones to search the Internet for additional ideas. Overall the students were assessed through an analysis of their dust collections as well as a teacher-made short answer test. Homework was scored as well as the quality of the discussions. For the final assessment, students, in groups of four, created videos to solve real-world applications of the curves they had studied.

Lindsey relied on the extensive reflective (Starkey IV) expectations of the electronic portfolio to critically analyse her teaching decisions, engaging in significant meta-cognitive actions. She videotaped two lessons and analysed them. Some of her reflections included:

- From the beginning brainstorming activity: "I found out that they could step up and work together to create what I believe to be a really strong (and long) list of applications.”

- In the $\mathrm{pH}$ experiments: "Throughout all of this I acted as a guide. I did not measure any pH, nor did I tell them which number it best matched. They asked each other and worked very collaboratively during this lesson. I did help them find the strip they would need to zoom into a more accurate $\mathrm{pH}$ measure.”

- Reviewing the actions of the students throughout the lessons: "Since I was a facilitator, students 
were more apt to think for themselves or ask a classmate. They had to think about what they were doing and then do it. Students learned about connections between mathematics and science. They also made more connections among the mathematics concepts of this unit. By acting as a facilitator, students learned through a hands-on synthesis experience.”

Lindsey clearly identified new comprehensions (Starkey $V$ ) about the subject, students and teaching:

- Teaching: "Prior to this year, I have not had much experience with student-centered, hands-on, technology-rich, discovery learning strategies.”

- Students and teaching: “The strategies that were implemented in the [electronic portfolio] collection were: discourse, questioning, inquiry, motivation, multiple representations, compare and contrast, cooperative and collaborative learning, providing feedback, and technology and science integration. Questioning, inquiry, and multiple representations were used with the one technology-enhanced lesson. The lesson using the Internet, Excel, and Google Docs used these strategies. It also used peer-review and self-assessment. Students had difficulty with the inquiry portion of the lesson. This, in turn, affected the questioning. They had very few problems with the multiple representations, peer review and self-assessments."

- $\quad$ Subject and teaching: "One other strategy I did not use, but read about, is team teaching. With two of my lessons - the ice lab and pH lab - I could have very easily worked with the science teacher - whose lab I was using - and planned to team teach the science concepts we were using as real-world data for mathematics. With team teaching, students could have made an even better connection to math, science, and technology."

- Students and teaching: "I also did not use positive reinforcement or recognition. I think doing this would have helped students become more motivated to do well.

- Students and teaching: "I have to admit that before the [electronic portfolio] collection, discourse was not a strategy I used often in my classroom. It was nice to have a positive experience and witness a natural discourse that stayed on topic. After the brainstorming, students worked in small groups and discussed the similarities and differences of the three functions. They partook in discourse while completing this task."

- $\quad$ Students: "Students, just like educators, become overwhelmed if too much is introduced at once. The changes need to be gradual."

The analysis of Lindsey’s technological pedagogical reasoning through her electronic portfolio work demonstrated that she had integrated multiple technologies with specific attention to communication, collaboration and inquiry around the mathematical ideas. She experimented with multiple instructional strategies that she had not used previously - whole group and small group discussions, inquiry learning and real-world applications while taking advantage of the affordances of the multiple technologies. Through an analysis of her videos, she recognised how the students interacted, shared ideas, and guided their understandings of the ideas. This recognition highlighted her most critical comprehension: "being a guide rather than the sole provider of information.” Her final reflection extended this recognition: "I will remember that as I plan other lessons.”

\section{Teachers' technological pedagogical reasoning and action with the systems approach}

The cross-case analysis revealed the teachers' pedagogical reasoning and action, in particular their reasoning and action with the systems pedagogical approach. The teachers who had taken both of the technology-enhanced courses prior to the electronic portfolio course had more experiences in thinking about teaching and learning with multiple technologies. Their cases provided more complete mental models supporting their pedagogical reasoning and actions incorporating the systems pedagogical approach. With the alignment of the critical components of developing mental models and the model for teacher pedagogical reasoning and action in the digital age (Starkey, 2010), this development of more complete and nuanced mental models suggests a more complex development of pedagogical reasoning. Moreover, across all seven cases, three themes emerged concerning their technological-pedagogicallyfocused mental models considering the full range of functions: cognitive, socio-cognitive, meta-cognitive and motivational. 


\section{Technological pedagogical reasoning 1: Incorporate a systems pedagogical approach by integrating technologies with instructional strategies}

The challenge of integrating multiple technologies for communication, collaboration and inquiry around mathematics appeared to engage them in deeper thinking about which technologies and how best to implement the technologies for engaging the students with the content challenges. While all teachers recognised the motivational function of the technologies, they expanded their thinking to the full range of functions as they described their mental models through the electronic portfolio artifacts and reflections.

Through their extensive reflections in the analyses of student learning with technologies, they often remarked about the various other functions.

- Cognitive function: The virtual manipulative "allowed the students to make an instant connection between the manipulative and the mathematical concept because the symbolic notation was also shown on the screen"

- Cognitive and motivational functions: "Technology allows students to interact with concepts in a visual, more engaging way. I found this to be true as I incorporated ... graphing calculators.”

- Socio-cognitive function: "The virtual manipulatives were nice ... students were able to work with partners more instead of their whole table group."

- Cognitive, socio-cognitive, and metacognitive functions: "When students worked in the groups with the graphing calculators, they helped each other when they were stuck. The groups also allowed students to explore many different equations of lines at the same time. They were exposed to many more possibilities of equations of lines than they would have been if I were leading the whole group. I wish I had a way for the groups to share what they found on their graphing calculators.”

These comments demonstrated the theme that the teachers viewed the technologies as being integrated with the instructional strategies. As one teacher noted: "Technology is not a tool which will automatically cause deeper learning for students. Technology must be integrated using instructional strategies; on its own, it is not an instructional strategy." Another teacher expanded on this recognition that she wished she had "worked in time to introduce the graphing calculator much earlier in the timeline." In essence, these teachers collectively found that students needed time to become familiar with the technologies and that they needed to attend to designing specific and purposeful instructional strategies to assure that students had the time to become familiar (some teachers used the phrase "play with the technology") prior to integrating it as a tool for learning specific mathematical ideas.

Technological pedagogical reasoning 2: Incorporate a systems pedagogical approach by integrating multiple technologies using active student engagement

The second theme centered on key instructional strategies to consider when integrating multiple technologies. Through their personal experiences in the online technology-enhanced courses (SED 520 and SED 521), these teachers were engaged in a purposeful orchestration of community, collaboration, inquiry and reflection activities (as shown in Table 1) where various technologies served specific purposes. Through their experiences, they experimented with these strategies prior to incorporating the systems pedagogical approach in their classrooms.

Thus, rather than presenting the ideas to the class as a whole, they used various small and large group activities to more actively involve the students with the ideas. One teacher indicated:

In the group activity on finding slopes and relating the slopes, students were unsure about how the slopes of intersecting lines related. It seemed like a difficult task. It felt like students were willing to take risks on explaining what they had found [with their technology tool] whereas if these questions or issues had come up in the large group I feel not as many students would be taking these risks.

Additional comments in the reflections found that having students work in groups, solving problems and exploring ideas through technology tasks "deepened their learning because they were developing their own plans for solving the problems." They claimed that this method was stronger than when they were 
"teaching the lesson" before the students tried to solve the problems. Plans for solving the problems came from students resulting in "a deeper knowledge from their explorations and discussions." In essence then, they claimed the strategy of, "Allowing students the time to develop understanding of concepts saves time in the long run." Thus, collectively, the seven teachers described the key instructional strategies as including "grouping, problem solving, questioning, and student discourse ... [allowing] the learning environment to be centered on students who are actively engaged.”

\section{Technological pedagogical reasoning 3: Incorporate a systems pedagogical approach through student-centered instruction}

Perhaps the strongest collective result as revealed through the teachers' pedagogical reasoning and action within the systems approach was the recognition of the importance of a student-centered instruction where the teacher was the facilitator or guide. Prior to the electronic portfolio class, all of the teachers confessed to primarily using teacher-directed instruction. Yet, as they experimented with new technologies and a systems pedagogical approach, they recognised through the five lessons the value of having students work collaboratively with the technologies, sharing their knowledge and understanding about the technologies and how those technologies might be used in understanding mathematics ideas. "I have always wanted student input during instruction, but I have not always let student input drive the instruction which took place.”

Multiple examples described the teachers developing mental model with respect to moving to a more student-centered instruction:

- "While I was standing by the group, other members would offer their understanding. Instead of jumping in right away and offering the explanation I would wait for students to work through it together arriving at a group consensus. I would ask more clarifying questions of them if they went off track."

- Another teacher described her experience as she orchestrated the discourse in a whole class session: "I had two separate students describe that the y-intercept indicated where on the graph the lines were drawn. Students asked many clarifying questions but I responded with more questions which required students to talk as group members to arrive at a conclusion.”

- " “Overall I want my classroom to be more student-centered and less teacher-centered.”

All seven teachers' technological pedagogical reasoning identified a student-centered instructional approach as an essential direction in the systems pedagogical approach. One of the teachers concluded:

It was really apparent during the [electronic portfolio] week. This whole aspect has changed my teaching strategies to include letting the students develop their work through discovery and struggle. I learned to step back and let them struggle and let them excel. It was very hard not to step in and help, but I did not and it was amazing how the students stepped up to the challenge. The work was so more meaningful when they all pitched in and figured out the answer together or the presenter looked up the information to get to the answer.

\section{Significance and implications}

As more and more technologies with features to support inquiry, communication and collaboration, not only in society but also in education, teachers are and will continue to be challenged to orchestrate if and how these technologies should be integrated as learning tools. This challenge presents a continuing need for tertiary education for practicing teachers at both the pre-service and in-service levels. This study demonstrates the blending of online instruction with practice-based experiences for in-service teachers, where they practiced their developing understandings in their own classrooms.

As a continuation of previous research (Niess \& Gillow-Wiles, 2013, 2014; Gillow-Wiles \& Niess, 2014), this study demonstrates how a systems technological pedagogical approach influences teachers' technological pedagogical reasoning as they make pedagogical choices for integrating multiple technologies. The study highlights ways to guide teacher knowledge development as they examine integrating multiple technologies in their own classrooms. The results provides empirically-supported educational techniques in tertiary education for practicing teachers as they continue to expand their knowledge for integrating the $21^{\text {st }}$ century technologies in their classrooms. 
The electronic portfolio process provided teachers with an opportunity to test and adapt their systems pedagogical approach, to examine the influence of the systems approach on their technological pedagogical reasoning. The use of the Starkey digital age pedagogical reasoning model (2010), supported by an alignment with the 2016 ISTE standards and the 4C's developed by the Partnership for $21^{\text {st }}$ Century Learning (2015), proved to be a strong analytic tool for the electronic portfolio, resulting in rich descriptions of the teachers' experiences, thinking and reflections as they examined their teaching with multiple technologies. The results of their implementation of that knowledge in their classrooms implied that when they had learning experiences with integrating multiple technologies using the systems pedagogical approach, their mental models (Krauskopf et al., 2012), as revealed through the electronic portfolio process, resulted in an expansion of their technological pedagogical reasoning and action for orchestrating and managing multiple technologies as inquiry, communication, and collaboration tools. Specifically, the technological pedagogical reasoning results revealed the teachers' recognition that incorporating a systems pedagogical approach involves: (1) integrating the technologies with instructional strategies, (2) integrating multiple technologies using active student engagement (such as grouping, problem solving, questioning and discourse), and (3) using a student-centered instruction as the primary approach. These results suggested that this systems pedagogical understanding is an important aspect of the teachers' development of their technological pedagogical reasoning and supports the transformation of their teacher knowledge - thus, at the core of their TPACK.

There are limitations with this study. This descriptive study involved a limited number of participants, making it difficult to generalise the results to a larger population. Furthermore, the context of the study was such that the class size of the courses was small during the research year, making it easier for the researchers to conduct the in depth analyses of the participants' engagements and interactions than if there were a larger number of people in each class. However, if the desired outcome of a teacher preparation program is teachers who have the knowledge to teach with technology systems as pedagogical tools, then technology systems as pedagogical tools must be part of their educational experience. These results hint at the effectiveness of the systems technological pedagogical approach and provide a beginning for further research into this conceptualisation of how best to bring the technological worlds of the classroom and the twenty-first century together in giving students the skills needed to be successful.

\section{References}

Akyol, Z., \& Garrison, D. R. (2008). The development of a community of inquiry over time in an online course: Understanding the progression and integration of social, cognitive, and teaching presence. Journal of Asynchronous Learning Networks, 12(3-4), 3-22.

Angeli, C., \& Valanides, N. (2005). Preservice elementary teachers as information and communication technology designers: An instructional systems design model based on an expended view of pedagogical content knowledge. Journal of Computer Assisted Learning, 21(4), 292-302. https://dx.doi.org/10.1111/j.1365-2729.2005.00135.x

Borko, H., Stecher, B., \& Kuffner, K. (2007). Using artifacts to characterize reform-oriented instruction: The Scoop Notebook and rating guide. (Technical Report 707). Los Angeles: CA: National Center for Research on Evaluation, Standards, and Student Testing), (ERIC Document Reproduction Service NO. ED495853).

Curtis, S., Gesler, W., Smith, G., \& Washburn, S. (2000). Approaches to sampling and case selection in qualitative researcher: Examples in the geography of health. Social Science \& Medicine, 50(7-8), 1000-1014. https://dx.doi.org/10.1016/S0277-9536(99)00350-0

Gillow-Wiles, H., \& Niess, M. (2014). A systems approach for integrating multiple technologies as important pedagogical tools for TPACK. In L. Liu \& D. Gibson (Eds.), Research highlights in technology and teacher education (pp. 51-58). Waynesville, NC: AACE.

Harris, J, Mishra, P., \& Koehler, M. (2009). Teachers’ technological pedagogical content knowledge and learning activity types; Curriculum-based technology integration reframed. Journal of Research on Technology in Education, 41(4), 393-416. https://dx.doi.org/10.1080/15391523.2009.10782536

International Society for Technology in Education. (2016). 2016 ISTE standards for students. Retrieved from https://www.iste.org/standards/standards/for-students-2016

Johnson-Laird, P. N. (1980). Mental models in cognitive science. Cognitive Science, 4, 71-115. https://dx.doi.org/10.1207/s15516709cog0401_4 
Kim, C., Kim, M. K., Lee, C., Spector, J. M., \& DeMeester, K. (2013). Teacher beliefs and technology integration. Teaching and Teacher Education, 29, 76-85.

https://dx.doi.org/10.1016/j.tate.2012.08.005

Krauskopf, K., Zahn, C., \& Hesse, F. W. (2012). Leveraging the affordances of Youtube: The role of pedagogical knowledge and mental models of technology functions for lesson planning with technology. Computers \& Education, 58(4), 1194-1206. https://dx.doi.org/10.1016/j.compedu.2011.12.010

Loughran, J. (2002). Effective reflective practice: In search of meaning in learning about teaching. Journal of Teacher Education, 53(1), 33-43. https://dx.doi.org/10.1177/0022487102053001004

Merriam-Webster's collegiate dictionary (10th ed.). (1999). Springfield, MA: Merriam-Webster Incorporated.

Meyer, C. (2001). A case in case study methodology. Field Methods, 13(4), 329-352. https://dx.doi.org/10.1177/1525822X0101300402

Myers, J. D., Chappell, A., Elder, M., Geist, A., \& Schwidder, L. (2003). Re-Integrating the research record. Computing in Science and Engineering, 5(3), 44-50. https://dx.doi.org/10.1109/MCISE.2003.1196306

Mishra, P., \& Koehler, M. J. (2006). Technological pedagogical content knowledge: A framework for teacher knowledge. Teachers College Record, 108(6), 1017-1054. https://dx.doi.org/10.1111/j.1467$\underline{9620.2006 .00684 . \mathrm{X}}$

Niess, M. L. (2005). Preparing teachers to teach science and mathematics with technology: Developing a technology pedagogical content knowledge. Teaching and Teacher Education, 21(5), 509-523. https://dx.doi.org/10.1016/j.tate.2005.03.006

Niess, M. L., \& Gillow-Wiles, H. (2013). Developing asynchronous online courses: Key instructional strategies in a social metacognitive constructivist learning trajectory. The Journal of Distance Education, 27(1), 1-23.

Niess, M. L. \& Gillow-Wiles, H. (2014). Transforming science and mathematics teachers' technological pedagogical content knowledge using a learning trajectory instructional approach. Journal of Technology and Teacher Education, 22(4), 497-520.

Partnership for $21^{\text {st }}$ Century Learning. (2015). Retrieved from https://www.P21.org//our-work/p21framework

Prensky, M. (2001). Digital natives, digital immigrants. On the Horizon, 9(5), 1-6. https://dx.doi.org/10.4135/9781483387765.n6

Putnam, R. T., \& Borko, H. (1997). Teacher learning: Implications of new views of cognition. International Handbook of Teachers and Teaching, 1123-1296. https://dx.doi.org/10.1007/978-94$\underline{011-4942-6 \quad 30}$

Roberts, B. (2002). Interaction, reflection and learning at a distance. Open Learning, 17(1). https://dx.doi.org/10.1080/02680510120110166

Saldana, J. (2009). The Coding Manual for Qualitative Researchers (1st ed.). London: Sage Publications Inc.

Scardamalia, M., \& Bereiter, C. (1993). Technologies for knowledge-building discourse. Communications of the ACM, 36(5), 37-41.

Schön. D. A. (1983). The reflective practitioner: How professionals think in action. New York, NY: Basic Books.

Seale, J., \& Cooper, M., (2010). E-learning and accessibility: An exploration of the potential of generic pedagogical tools. Computers \& Education, 54(4), 1107-1116. https://dx.doi.org/10.1016/j.compedu.2009.10.017

Shulman, L. S. (1987). Knowledge and teaching: Foundations of the new reform. Harvard Educational Review, 57(1), 1-21. https://dx.doi.org/10.17763/haer.57.1.j463w79r56455411

Starkey, L. (2010). Teachers’ pedagogical reasoning and action in the digital age. Teachers and Teaching: Theory and Practice, 16(2), 233-244.

Thoughtful Learning Organization. (2016). Retrieved from https://k12.toughtfullearning.com/FAQ/whatare-learning-skills

Westbrook, I. (2006). Mental models: A theoretical overview and preliminary study. Journal of Information Science, 32(6), 563-579. https://dx.doi.org/10.1177/0165551506068134

Wheatley, G. H. (1992). The role of reflection in mathematics learning. Educational Studies in Mathematics, 23(5), 529-541. https://dx.doi.org/10.1007/BF00571471 
Wilson, S. M., Shulman, L. S., \& Richert, A. E. (1987). 150 different ways of knowing: Representations of knowledge in teaching. In J. Calderhead (Ed.), Exploring teachers'tThinking (pp. 104-124), CiteULike.

Corresponding author: Margaret Niess, niessm@oregonstate.edu

Australasian Journal of Educational Technology (c) 2017.

Please cite as: Niess, M., \& Gillow-Wiles, H. (2017). Expanding teachers’ technological pedagogical reasoning with a systems pedagogical approach. Australasian Journal of Educational Technology, 33(3), 77-95. https://doi.org/10.14742/ajet.3473 